\title{
Assessment of ambient air quality in urban centres of Haryana (India) in relation to different anthropogenic activities and health risks
}

\author{
C. P. Kaushik*, Ravindra Khaiwal ${ }^{\#}$, Krishan Yadav, Surender Mehta and A. K. \\ Haritash \\ Department of Environmental Science \& Engineering, Guru Jambheshwar University, \\ Hisar-125001, Haryana, India. \\ ("author for Correspondence-e-mail: cpkaushik@rediffmail.com)
}

\begin{abstract}
Considering the mounting evidences of the effects of air pollution on health, the present study was undertaken to assess the ambient air quality status in the fast growing urban centres of Haryana state, India. The samples were collected for total suspended particulate matter (TSPM), respirable suspended particulate matter $\left(\mathrm{PM}_{10}\right)$, sulfur dioxide $\left(\mathrm{SO}_{2}\right)$, and for oxides of nitrogen $\left(\mathrm{NO}_{2}\right)$ during different seasons from 8 districts of Haryana during January, 1999 to September, 2000. The four types of sampling sites with different anthropogenic activities i.e. residential, sensitive, commercial and industrial were identified in each city. The ambient air concentration of TSPM and $\mathrm{PM}_{10}$ observed was well above the prescribed standards at almost all the sites. The average ambient air concentrations of $\mathrm{SO}_{2}$ and $\mathrm{NO}_{2}$ were found below the permissible limits at all the centres. Comparatively higher concentration of $\mathrm{SO}_{2}$ was observed during winter seasons, which seems to be related with the enhanced combustion of fuel for space heating and comparatively stable atmospheric conditions. Air Quality Index (AQI) prepared for these cities shows that residential, sensitive and commercial areas were moderately to severely polluted which is a cause of concern for the residents of these cities. The high levels of TSPM and $\mathrm{SO}_{2}$ especially in winter are of major health concern because of their synergistic action. The data from Hisar city reveals a significant increase in the total number of hospital visits/admissions of the patients with acute respiratory diseases during winter season when the level of air pollutants was high.
\end{abstract}

Keywords: urban centres, TSPM, PM 10 , vehicles, air quality index, human health.

\# Present address: Micro and Trace Analysis Center, Department of Chemistry, University of Antwerp, Universiteitsplein 1, B-2610, Antwerp, Belgium. (e-mail: khaiwal.ravindra@ua.ac.be or Khaiwal@yahoo.com) 


\section{Introduction}

Air pollution has long been recognized as a potentially lethal form of pollution. Entry of pollutants into the atmosphere occurs in the form of gases or particles. Continuous mixing, transformation and trans-boundary transportation of air pollutants make air quality of a locality unpredictable. The growth of population, industry and number of vehicles and improper implementation of stringent emission standards make the problem of air pollution still worse (Ravindra et. al., 2001). The WHO/UNEP report (1992) reveals air pollution problems in metropolitan cities of India as they are heading the list of the most polluted cities of the world. India has 23 major cities of over 1 million people and ambient air pollution levels exceed the WHO standards in many of them (Gupta et. al, 2002). The single most important factor responsible for the deterioration of air quality in the cities is the exponential increase in the number of vehicles. Vehicular pollution contributes to $70 \%$ of total pollution in Delhi, $52 \%$ in Mumbai and $30 \%$ in Calcutta (C.P.C.B., 2003; Gokhale \& Patil, 2004; Ravindra et al., 2005).

Pollution in these cities has associated serious to moderate health problems due to high levels of total suspended particulate matter (TSPM), sulfur dioxide $\left(\mathrm{SO}_{2}\right)$ and lead (The World Bank report, 1997). At least 500,000 premature deaths and 4 to 5 million new cases of chronic bronchitis are reported each year (WHO, 1992). Further 4\% to $8 \%$ of premature deaths on a global scale are due to exposure of high levels of particulate matter in ambient air (WHO, 2000). Ambient air levels exceeding the WHO levels in 36 major Indian cities and towns results in 40 thousand premature deaths, around 19 million respiratory hospital admissions and sickness requiring medical treatment and also 1.2 billion incidences of minor sickness annually (Brandon \& Homman, 1995).

Despite the increasing evidence of negative impact of air quality on human health (Dockery et al., 1993a,b; Pope et al., 1995; Kunzli et al., 2000), not much data on ambient air quality, a prerequisite for health studies, is available for most of the medium size cities or towns in India, although a large population lives in these cities or towns. Not much information on the air quality of Haryana, which has experienced rapid industrial and vehicular growth during last few decades, is available. In the present study, an attempt has been made to assess the prevailing concentration and trends of the TSPM, $\mathrm{PM}_{10}, \mathrm{SO}_{2}$ and $\mathrm{NO}_{2}$ in the fast growing urban centers of various cities in relation to 
different anthropogenic activities. Furthermore, the epidemiological data of Hisar city was evaluated in relation to the health risks of these criteria pollutants.

\section{Materials and Methods}

\subsection{Site specifications}

Haryana is a fast developing state of north India situated at $30^{\circ} 30^{\prime} \mathrm{N}, 74^{0} 60^{\prime} \mathrm{E}$ and around 210-275 m above mean sea level with an area of 44,000 $\mathrm{Km}^{2}$. The population is about 21.1 million (2001). Approximately 29\% people reside in cities. The cities are dominated by various small, medium and large-scale industries. From 1966 to 1997, the total number of industries has increase up to 7 time, whereas a 75 times increase in total number of vehicle has been registered.

Eight major cities namely, Bhiwani, Gurgaon, Faridabad, Sonipat, Panipat, Yamunanagar, Panchkula and Hisar were selected for the ambient air quality monitoring (Fig.1), which have observed considerable growth in commercial and industrial sector during last few years. A total of four sampling sites were selected in each city on the basis of differential population activity and characteristics, which includes residential (R), sensitive (S), commercial (C) and industrial (I) areas. In most of the cases district civil hospital was selected as the sensitive site.

\subsection{Sampling and analytical procedure}

APM-460 respirable dust samplers (RDS) with provision for gaseous sampling APM-411 (Envirotech, New Delhi) was used for measuring the concentrations of TSPM, $\mathrm{PM}_{10}, \mathrm{NO}_{2}$ and $\mathrm{SO}_{2}$ in the ambient air. The sampling inlet was placed 1-3 meter above the ground level, depending upon the site available for the RDS. The APM-460 Respirable Dust Sampler has been provided with a cyclone. The cyclone has been designed to provide separation of $\mathrm{PM}_{10}$ particles. Atmospheric air was drawn for $\sim 24$ hours through the cyclone and $20 \times 25 \mathrm{~cm}$ glass fiber filter (GFF) sheet at a flow rate of 0.8 to $1.2 \mathrm{~m}^{3} \mathrm{~min}^{-1}$ and finally the average flow rate was calculated.

As the air with suspended particulate enters the cyclone, coarse non-respirable dust is separated from the air stream by centrifugal forces. The suspended particulate matter falls through the cyclone's conical hopper and gets collected in the cyclonic-cup. The fine dust comprising the respirable fraction of TSPM passes through the cyclone and 
gets collected on GFF. The amount of non-respirable suspended particulate matter (NRSPM) and respirable particulate per unit volume of air passed was calculated on the basis of the difference between initial and final weights of the cyclone cup and that of the filter paper, and the total volume of the air drawn during sampling. Mass concentration of TSPM was calculated by adding the concentration of $\mathrm{PM}_{10}$ and NRSPM. For gaseous $\left(\mathrm{SO}_{2}\right.$ and $\left.\mathrm{NO}_{2}\right)$ sampling the impingers were exposed for $\sim 24$ hour at an impingement rate of 1 Litre $\min ^{-1}$ to get one sample in a day. $\mathrm{SO}_{2}$ was analyzed by the West-Gaeke method on Spectronic-21 spectrophotometer at wavelength of $560 \mathrm{~nm} . \mathrm{NO}_{2}$ was analyzed employing the Jacob- Hochheiser modified method on a spectrophotometer at wavelength of $540 \mathrm{~nm}$ (Lodge, 1989).

\subsection{Air quality index (AQI)}

The Air Quality Index (AQI) was calculated using the method suggested by Tiwari and Ali (1987). First of all, the air quality rating of each pollutant was calculated by the following formula:

$$
\mathrm{Q}=100 \frac{V}{V s}
$$

Where, Q represents quality rating, $V$ the observed-value of the pollutant and $V s$ the standard value recommended for that pollutant. The Vs values used are as National Ambient Air Quality Standards (Table 1) for different areas.

If total ' $n$ ' number of pollutants were considered for air quality monitoring, geometric mean of these ' $n$ ' number of quality rating is calculated in the following way:

$$
g=\operatorname{antilog} \frac{\left(\log _{a}+\log _{b}+\log _{c}+\ldots \log _{x}\right)}{n}
$$

Where ' $\mathrm{g}$ ' is geometric mean, while ' $\mathrm{a}, \mathrm{b}$, c, and $\mathrm{x}$ ' represents different value of quality rating, and ' $\mathrm{n}$ ' is number of values of quality rating. 


\section{Results and Discussions}

\subsection{Site-specific variations}

The average concentration of various criteria pollutants is shown in Table 2. The ambient air concentration of TSPM was observed more than the stipulated standards at almost all the sites. It ranged from $158.3 \mu \mathrm{g} / \mathrm{m}^{3}$ (Sonipat) to $868.0 \mu \mathrm{g} / \mathrm{m}^{3}$ (Faridabad) in residential areas and $104.1 \mu \mathrm{g} / \mathrm{m}^{3}$ (Bhiwani) to $812.1 \mu \mathrm{g} / \mathrm{m}^{3}$ (Hisar) in sensitive areas. Commercial areas also had TSPM concentration above the recommended limit (200 $\mu \mathrm{g} / \mathrm{m}^{3}$ ) and ranged from $191.3 \mu \mathrm{g} / \mathrm{m}^{3}$ (Hisar) to $1756.6 \mu \mathrm{g} / \mathrm{m}^{3}$ (Sonipat), whereas the TSPM levels in industrial areas varies from $126.4 \mu \mathrm{g} / \mathrm{m}^{3}$ (Panipat) to $1075.8 \mu \mathrm{g} / \mathrm{m}^{3}$ (Yamunanagar). Further, it was observed that average concentrations of PM10 ranged from $32.0 \mu \mathrm{g} / \mathrm{m}^{3}$ in sensitive area in Panchkula to $430.0 \mu \mathrm{g} / \mathrm{m}^{3}$ in commercial area in Sonipat and were found lower than the non-respirable suspended particulate matter (range from $39.5 \mu \mathrm{g} / \mathrm{m}^{3}$ in Bhiwani to $1493 \mu \mathrm{g} / \mathrm{m}^{3}$ in Hisar).

The WHO reports $(1998,1999)$ also shows that, most of the cities in developing world including several cities of India experience the TSPM level above $300 \mu \mathrm{g} / \mathrm{m}^{3}$. The data on $\mathrm{PM}_{10}$ is available only for a limited number of cities which reveals that the annual average $\mathrm{PM}_{10}$ level ranged from 50 to $100 \mu \mathrm{g} / \mathrm{m}^{3}$ in the year $1995 / 1996$. The highest concentration exceeding $250 \mu \mathrm{g} / \mathrm{m}^{3}$ were observed in Kolkata and New Delhi. Comparison of our results with WHO reports reveals higher levels of particulate matter in the present study. The probable reason for the high levels of atmospheric TSPM and $\mathrm{PM}_{10}$ could be due to industrial and agriculture activities.

Gaseous pollutants $\left(\mathrm{SO}_{2}\right.$ and $\left.\mathrm{NO}_{2}\right)$ were found below the permissible limits at all the centres except at few sites in Gurgaon, Faridabad, Sonipat, Panipat and Yamunanagar in January, 1999. The levels of $\mathrm{SO}_{2}$ during year 2000 sampling period were well below the permissible limit at all the sites. The $\mathrm{SO}_{2}$ concentrations in the ambient air in cities of developed countries have mostly decreased in the last two or three decades, due to strict emission control, increased use of low sulfur content fuel and industrial restructuring. Consequently, the high $\mathrm{SO}_{2}$ concentrations in earlier decades have been replaced by annual mean concentration of about $20-40 \mu \mathrm{g} / \mathrm{m}^{3}$ in most cities of the developing countries, and the daily average values rarely exceed $125 \mu \mathrm{g} / \mathrm{m}^{3}$ (WHO, 1998). The levels of $\mathrm{SO}_{2}$ observed in the present study are in conformity with the above observation. 
The residential, commercial and industrial areas in all the cities exhibited lower concentration of whereas sensitive locations in few cities exhibited higher levels $\mathrm{NO}_{2}$ compared to the prescribed limits. The $\mathrm{NO}_{2}$ level ranged from $10.6 \mu \mathrm{g} / \mathrm{m}^{3}$ (Hisar) to 83.6 $\mu \mathrm{g} / \mathrm{m}^{3}$ (Gurgaon) and $17.7 \mu \mathrm{g} / \mathrm{m}^{3}$ (Bhiwani) to $117.1 \mu \mathrm{g} / \mathrm{m}^{3}$ (Yamunanagar) in sensitive and industrial areas, respectively. In most of the cities the annual mean concentration of $\mathrm{NO}_{2}$ remains moderates or low, not exceeding $40 \mu \mathrm{g} / \mathrm{m}^{3}$ (WHO, 2000). However, in the preseny study, the $\mathrm{NO}_{2}$ values recorded were relatively high.The highest $\mathrm{NO}_{2}$ levels and the increasing trends are observed in cities with high and increasing vehicular traffic.

Comparative account of cities based on average pollutant concentration shows that Sonipat, Faridabad, Yamunanagar and Hisar were the most polluted followed by Gurgaon, Panipat, Panchkula and Bhiwani (Fig 2). Similar results have been observed by Bhanarkar et al. (2002) in a study to assess the air pollution concentrations in Haryana sub region.

Since fine particulate matter has associated heavy metals and other priority pollutants on its surface, it can pose serious threat to human health with special reference to the respiratory disorders (Dockery et al., 1993a,b; pope et al., 1995). The association of toxic elements with $\mathrm{PM}_{10}$ and smaller particles can be even more harmful as these can penetrate deep into the respiratory tract. Hence, high levels of TSPM particularly of $\mathrm{PM}_{10}$ are of major concern in health perspectives and there is an urgent need to regulate the ambient air quality especially in sensitive areas because of exposure of sensitive population i.e. the patients.

\subsection{Seasonal variations}

Seasonal comparison of $\mathrm{SO}_{2}$ and $\mathrm{NO}_{2}$ levels shows a higher value in winter than observed in pre-monsoon and post monsoon seasons. Significantly high levels of $\mathrm{SO}_{2}$ were observed in January 1999 in comparison to the subsequent sampling period. The probable reason for a sharp fall in $\mathrm{SO}_{2}$ concentration seems to be related with the adoption of EURO I (European emissions and fuel regulations) standards nationwide in the year 2000 for four wheeled light duty and heavy duty vehicles and hence the use of low sulphur diesel (LSD) was recommended and observed. However, higher concentration of $\mathrm{SO}_{2}$ noticed in few residential and commercial areas during winter season could be related to the enhanced combustion of fuel for space heating. Apart from 
it, comparatively stable atmospheric conditions in winter may also account for built up concentration of ambient air pollutants (Ravindra et al., 2003 and 2005). The high $\mathrm{NO}_{2}$ concentrations, combined with the intensive UV radiation, results in photochemical smog with high $\mathrm{O}_{3}$ concentration, which can adversely affect the human health. Studies conducted by Singh et al., (1997) and Reddy et al., (2004) also confirm similar phenomena in New Delhi and Vishakhapatnam, respectively.

A relative fall in TSPM, $\mathrm{PM}_{10} \mathrm{SO}_{2}$ and $\mathrm{NO}_{2}$ levels during post-monsoon may be due to the washout of these air pollutants by monsoon rains. Ravindra et al. (2003) have also reported a significant decrease in $\mathrm{SO}_{2}(\sim 38 \%), \mathrm{NO}_{2}(\sim 44 \%)$ and TSPM ( 48\%) levels just after the initial shower of monsoon in Delhi. An increased concentration of TSPM and $\mathrm{PM}_{10}$ was observed in pre-monsoon. The sources of such particulates are vehicular and industrial emissions as also the suspended fine dust carried by the transboundary winds from Rajasthan. This unique behavior of winds is generally observed during months each year in Haryana.

\subsection{Air Quality Index (AQI)}

AQI is developed to provide the information about air quality. From a series of observations, an index (a ratio or number) is derived which is an indicator or measure of some condition or property. The concentration of the major pollutants are monitored and subsequently are converted into the AQI (Table 3) using standard formulae, which in the present case are defined in experimental section. In the present investigation, the TSPM, $\mathrm{PM}_{10}, \mathrm{SO}_{2}$ and $\mathrm{NO}_{2}$ level in various cities have been used to calculate AQI. The higher value of an index refers to a greater level of air pollution and consequently greater health risks.

The categorization of ambient air quality with respect to the AQI is presented in Table 3. On the basis of AQI, it can be seen that the residential, sensitive and commercial areas were moderately to severely polluted (AQI 50-125) and whereas the industrial areas, on an average, lie in the range of fairly clean (AQI 25-50) to moderately polluted (AQI 50-75) except the industrial area in Yamunanagar, which is moderately to heavily polluted. It should be noted that for industrial area the norms for standard prescribed concentration in comparison to other sites have been relaxed. 


\subsection{Health risk study of Hisar city}

Various air pollutants are known to cause/ aggravate cardiac and respiratory diseases like asthma, bronchitis and emphysema. Individuals with cardiovascular diseases or chronic lung diseases, children and elderly are more susceptible (EPA, 2000). Though the mechanisms are not fully explained, epidemiological evidence suggests that outdoor air pollution is a contributing cause to morbidity and mortality (Bates, 1992; Katsouyanui et al.; Kunzli et al., 2000). State-of-the-art epidemiological research has found consistent and coherent associations between air pollution and various symptoms. Most of the air pollution studies have been conducted in the developed countries. Epidemiological data on the health effects of air pollutants are not abundant for most of the developing countries, where a major proportion of the population lives in environmentally poor conditions.

In the present study the data related to visit of patient for acute respiratory disease was obtained (Table 4) from district civil hospital of Hisar city for the year 1999 and 2002. The comparison of the data shows a significant fall $(<40 \%)$ in the total number of patient who visited during 2002, which besides other reasons can be related to the fall in $\mathrm{SO}_{2}$ and $\mathrm{NO}_{2}$ concentration in 2002 after the adoption on Euro I norms. It was also noticed that a large number of patients visited hospitals during the winter season in comparison to other seasons. During winter, cold weather condition with high levels of pollutants may aggravate the condition of sensitive population and hence results in increased hospital visits in the winter months.

\section{Conclusion}

Based on the study, it can be easily concluded that emission of $\mathrm{SO}_{2}$ and $\mathrm{NO}_{2}$ has considerably been reduced after the adoption of LSD and catalytic converters in vehicles. $\mathrm{PM}_{10}$ and TSPM are the chief air pollutants in most of the cities of Haryana, which pose the health risks either alone, or in combination with other pollutants. The ambient concentration of all the air pollutants decrease in post-monsoon as the monsoonal rain is responsible for the washing of ambient air pollutants. When compared with respective standards, the AQI of residential and commercial areas is high and indicates the possible threat of air pollutants to the residents of these localities. The present study also reveals a significant increase in the total number of patients admitted for respiratory problems in winter. 


\section{References}

Bates D., Health indices of the adverse effects of air pollution: the question of coherence. Environ. Res. 59 (1992), pp. 336-349.

Bhanarkar, A.D., Gajghate, D.G. and Hasan, M.Z.: 2002, Air pollution concentrations in Haryana subregion, India, Bull. Environ. Contam. Toxicol. 69, 690-695.

Brandon C., HommanK. : 1995, The cost of inaction: Valuing the economy-wide cost of environmental degradation in India, Worldbank, Washington DC.

C.P.C.B.: 2003, 'Parivesh: Polycyclic Aromatic Hydrocarbons (PAHs) in air and their effects on human health' November 2003, Central Pollution Control Board, Ministry of Environment and Forest, Delhi-32, Page 20. (http://www.cpcb.delhi.nic.in/ph/ch81103.htm).

Dockery D.W., Pope C.A., Xu X., Spengler J.D., Ware J.H., Fay M.E., Ferris B., and Speize, F.: 1993a, 'An association between air pollution and morality in six US cities', New Eng. J. Med., 329, 1753-1759.

Dockery D.W., Schwartz J., and Spengler, D.:1993b, 'Air pollution and daily mortality: associations with particulates and acid Aerosols', Environ. Res. 59, 362-373 (1993b).

EPA: 2000, Air Quality Index. A guide to air quality and your health. EPA 454/R-00005, Washington DC.

Gokhale, S.B. and Patil, R.S.: 2004, Size distribution of aerosols (PM10) and Lead (Pb) near traffic intersections in Mumbai (India), Environ. Monit. Assess. 95, 311-324.

Gupta, H.K., Gupta VB, Rao, C.V.C, Gajghate, D.G. and Hasan, M.Z.: 2002, 'Urban air quality and its management strategy for a metropolitan city of India', Bull. Environ. Contam. Toxicol. 68, 347-354.

Katsouyanni K., Touloumi G. and Spix, C.:1997,' Short-term effects of ambient sulphur dioxide and particulate matter on mortality in 12 European cities: results from times series data from the APHEA project', BMJ 314, 1658-1663.

Künzli N., Kaiser R., Medina S., Studnicka M., Chanel O., Filliger P., Herry M., Horak, Jr F., Puybonnieux-Texier V., Quénel P., Schneider J., Seethaler R., Vergnaud and Sommer, H.: 2000, 'Public-health impact of outdoor and traffic-related air pollution: a European assessment', The Lancet 356, 795-801. 
Lodge J.P.: 1989, 'Methods of air sampling and analysis', (3 ${ }^{\text {rd }}$ edition), Lewes Publisher Inc, Chelsea, Michigan, 403-406.

Pope A., Thun M., and Namboodiri M.: 1995, 'Particulate air pollution as a predictor of mortality in a prospective study of US adults', Am J Respir Crit Care Med 151 $669-674$.

Ravindra K, Mittal A. K. and Van Grieken, R.: 2001, Health risk assessment of urban suspended particulate matter with special reference to polycyclic aromatic hydrocarbons: A review. Rev.Environ. Health 16, 169-189, 2001.

Ravindra K., Mor S., Ameena, Kamyotra J.S. and Kaushik C.P.: 2003, Variation in spatial pattern of criteria air pollutants before and during initial rain of monsoon, Environ. Monit. Assess. 87, 145-153.

Ravindra, K., Mor, S., and Kaushik C.P.: 2003. Short-term variation in air quality associated with firework event: A case study. J. Environ. Monit. 5, 260-264.

Ravindra, K., Wauters, E., Taygi, S. K., Mor S., and Grieken R. V.: 2005. Assessment of air quality after the implementation of $\mathrm{CNG}$ as fuel in public transport in Delhi, India. Environ. Monit. Asses., In press.

Reddy, M.K., Ramarao, K.G. and Rammohanrao, I.: 2004, Air pollution status of Visakhapatnam (India) - Indices basis, Environ. Monit. Asses. 95, 1-12.

The World Bank: 1997, Urban air quality management strategy in Asia (URBAIR). 1818. H street NW, Washington DC: 20433 USA.

Tiwari, T.N. and Ali, M.: 1987, Air Quality Index for Calcutta and its monthly variation for various localities. Indian J. Environ. Prot. 7, 172-176.

WHO, 2000, Guidelines for air quality, World Health Organization, Genewa. (http://www.who.int/peh/)

WHO/UNEP Report: 1992, Urban air pollution in mega-cities of the world. World Health Organisation and United Nations Environment Programme. Blackwell Publishers, 108 Cowley Road, Oxford OX4 1JF Cambridge, UK.

WHO: 1998, 'Healthy cities air management information system', AMIS 2.0. CD ROM. World Health Organization, Geneva.

WHO: 1999, 'Guidelines for air quality', World Health Organization, Geneva. 


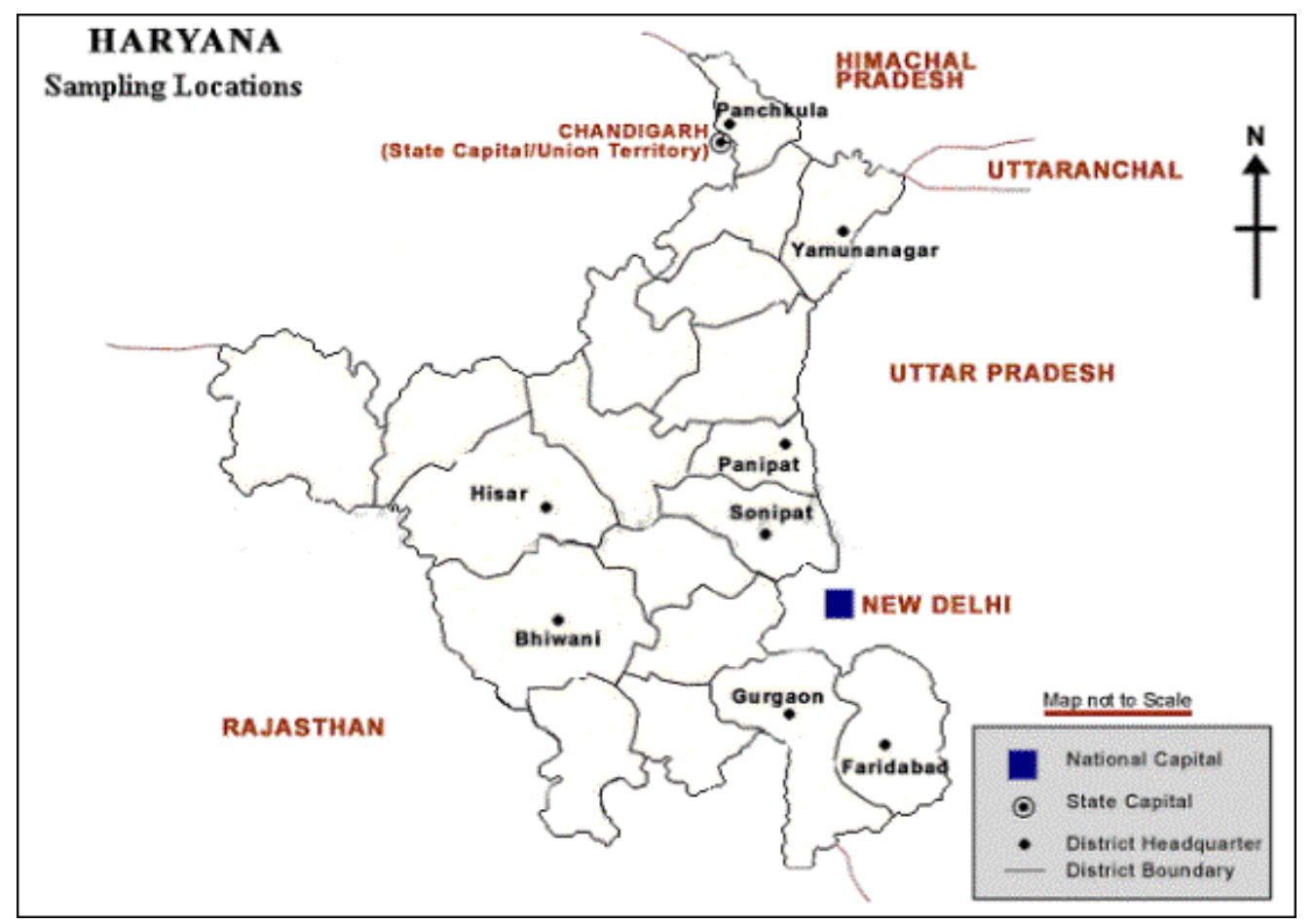

Fig 1: Location of different cities selected for the sampling.

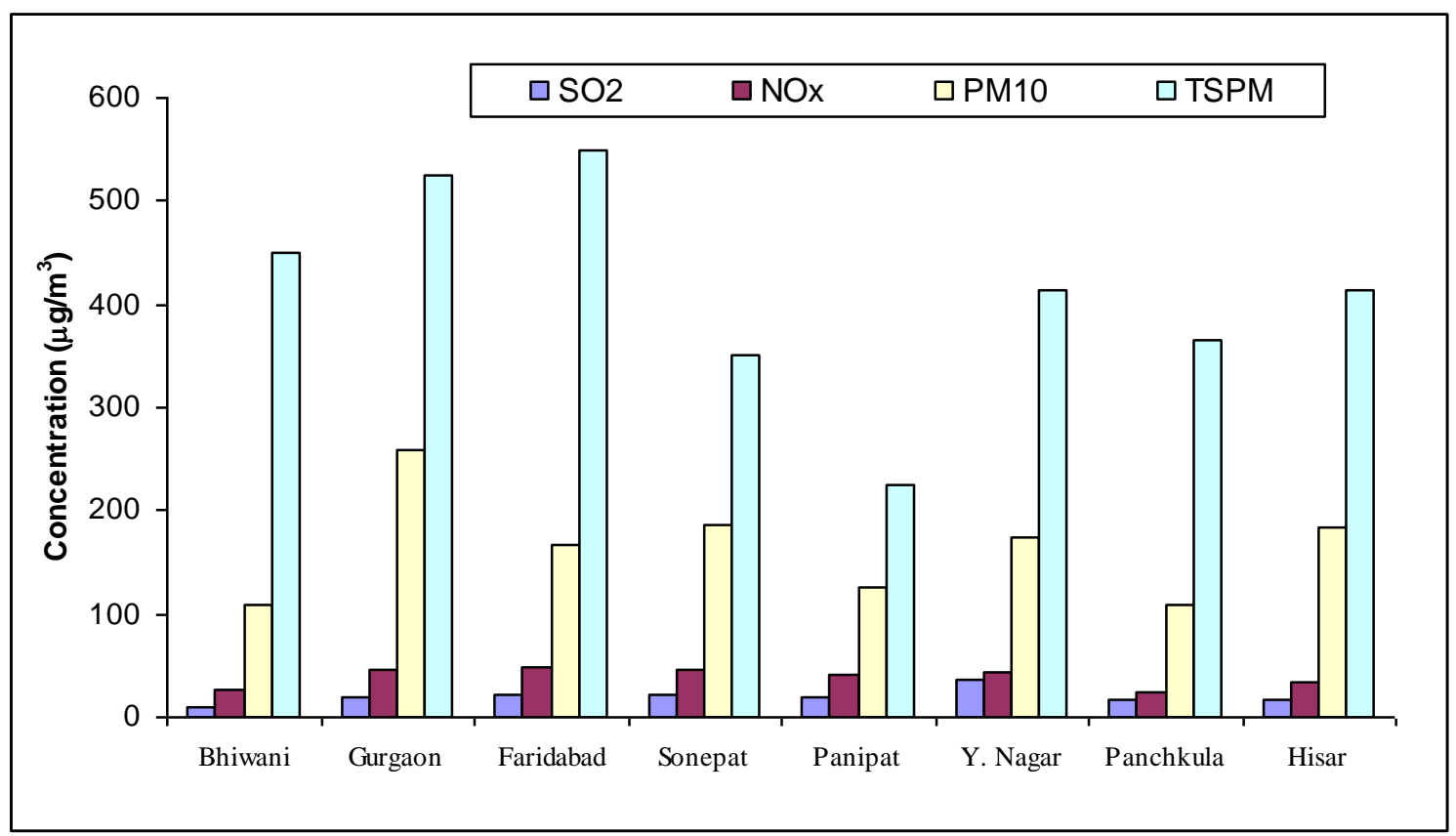

Fig 2: Average concentration of different pollutants $\left(\mu \mathrm{g} / \mathrm{m}^{3}\right)$ in different cities of Haryana 

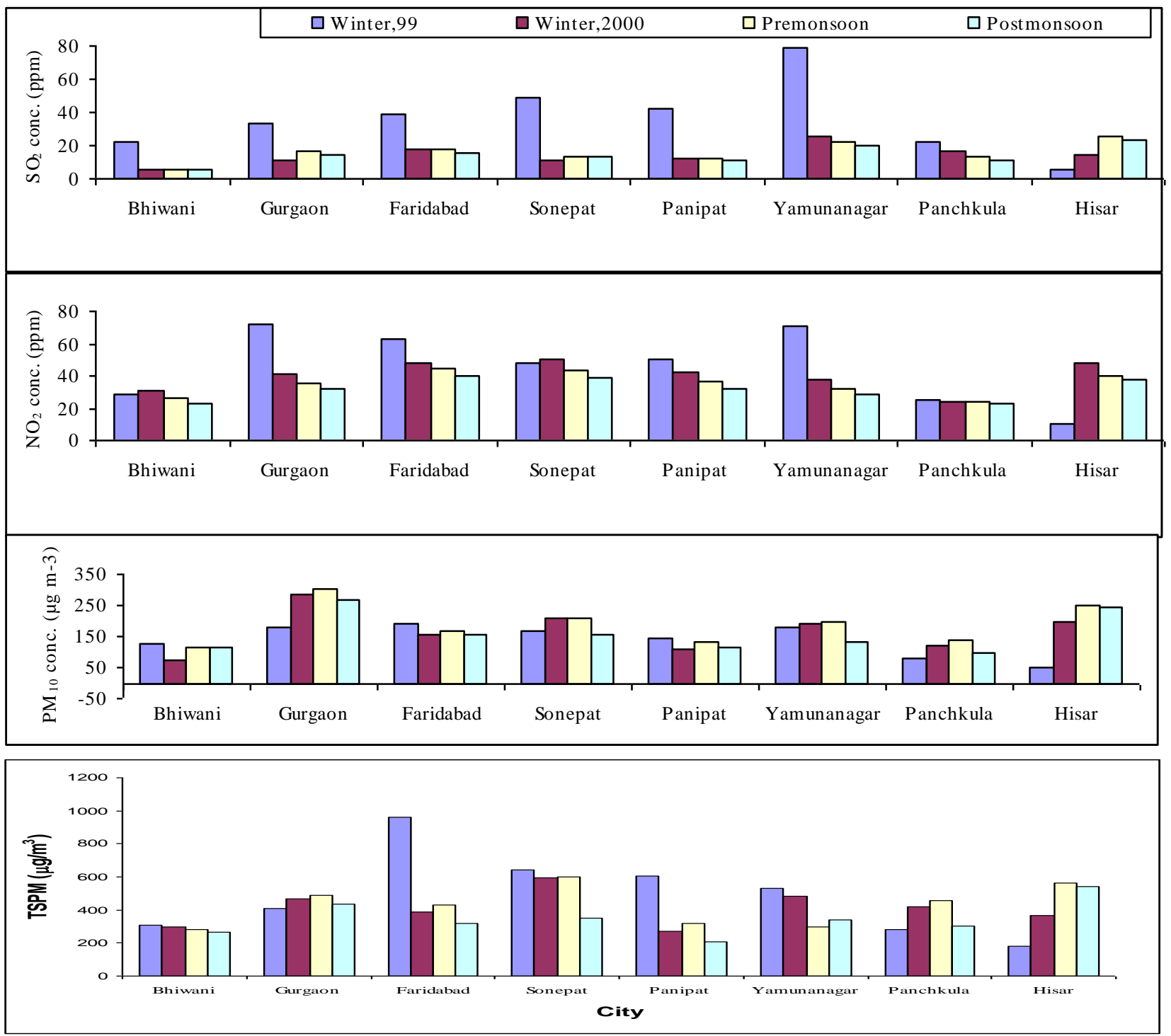

Fig 3: Variation in average $\mathrm{SO}_{2}, \mathrm{NO}_{2}, \mathrm{PM}_{10}$ and TSPM levels during different season in various cities of Haryana. 
Table 1: National ambient air quality standards for 24 time weighted average.

\begin{tabular}{|c|c|c|c|}
\hline \multirow{2}{*}{ Pollutants } & \multicolumn{3}{|c|}{ Concentration in ambient air $\left(\mu \mathrm{g} / \mathrm{m}^{3}\right)$} \\
\cline { 2 - 4 } & Sensitive area & Industrial area & Residential area \\
\hline $\mathrm{SO}_{2}$ & 30 & 120 & 80 \\
\hline $\mathrm{NO}_{2}$ & 30 & 120 & 80 \\
\hline $\mathrm{TSPM}$ & 100 & 500 & 200 \\
\hline
\end{tabular}


Table 2: The average ambient air concentration of pollutants $\left(\mu \mathrm{g} / \mathrm{m}^{3}\right)$ and AQI for different cities of Haryana.

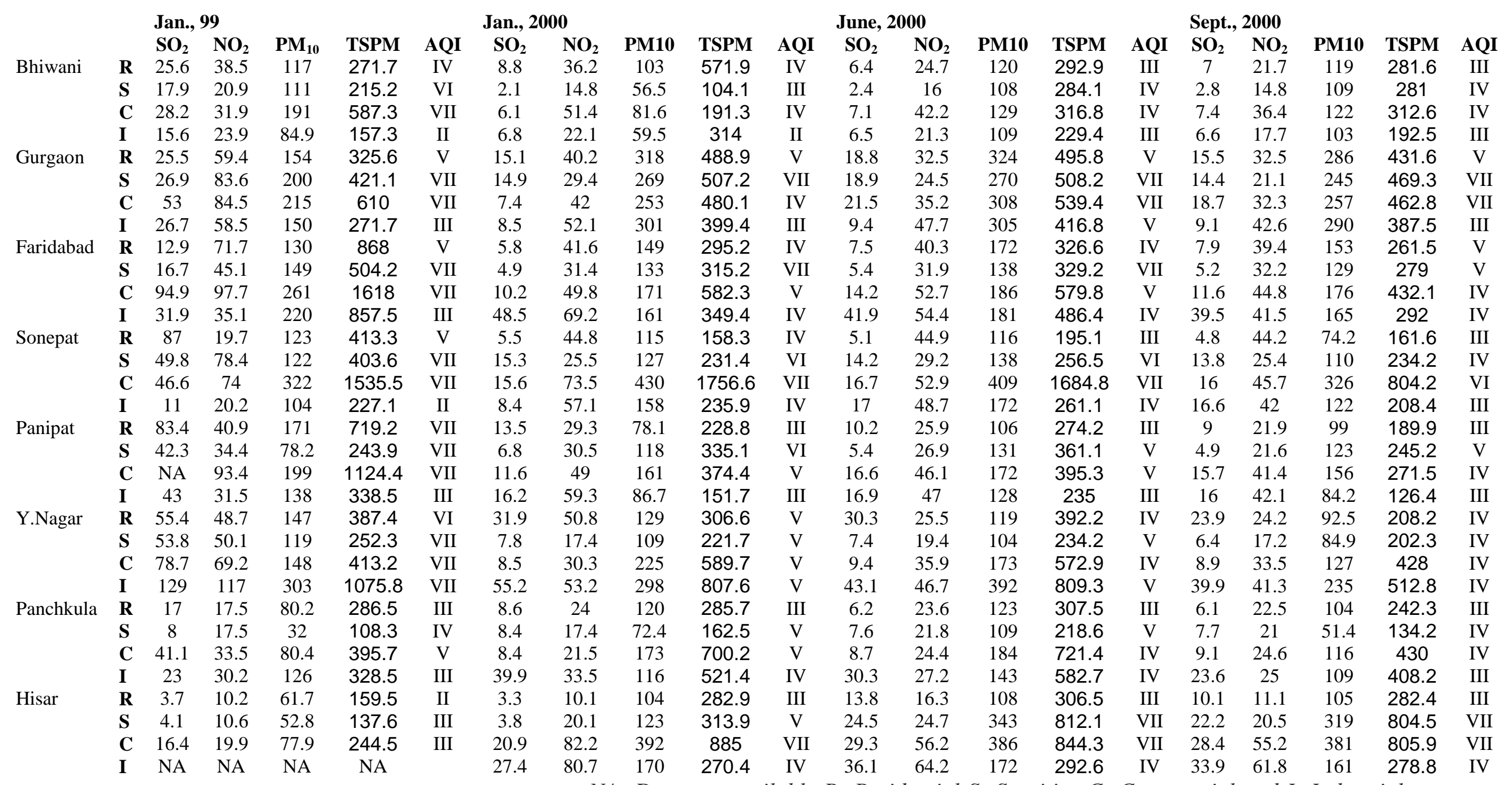

NA-Data not available;R-Residential;S-Sensitive;C-Commercial and I-Industrial 
Table 3: Air quality categories based on AQI.

\begin{tabular}{|ccc|}
\hline Category & AQI of ambient air & Description of ambient air quality \\
\hline I & Below 10 & Very clean \\
II & Between 10-25 & Clean \\
III & Between 25-50 & Fairly clean \\
IV & Between 50-75 & Moderately polluted \\
V & Between 75- 100 & Polluted \\
VI & Between 100-125 & Heavily polluted \\
VII & Above 125 & Severely polluted \\
\hline
\end{tabular}


Table 4: Data on patients with respiratory disease, collected from District Civil Hospital, Hisar.

\begin{tabular}{|c|c|c|c|c|c|c|c|}
\hline \multicolumn{2}{|c|}{ Months/ Year } & \multicolumn{3}{|c|}{ Patient visited } & \multicolumn{3}{|c|}{ Patient admitted } \\
\hline & & Male & Female & Total & Male & Female & Total \\
\hline \multirow[t]{2}{*}{ January } & 1999 & $*$ & $*$ & 995 & * & $*$ & 31 \\
\hline & 2002 & 287 & 251 & 538 & 47 & 31 & 78 \\
\hline \multirow[t]{2}{*}{ February } & 1999 & 249 & 201 & 450 & 16 & 12 & 28 \\
\hline & 2002 & * & $*$ & * & * & $*$ & $*$ \\
\hline \multirow[t]{2}{*}{ March } & 1999 & 209 & 128 & 347 & 19 & 12 & 31 \\
\hline & 2002 & 138 & 72 & 210 & 12 & 9 & 21 \\
\hline \multirow[t]{2}{*}{ April } & 1999 & 168 & 140 & 318 & 15 & 5 & 20 \\
\hline & 2002 & $*$ & $*$ & $*$ & * & $*$ & $*$ \\
\hline \multirow{2}{*}{ May } & 1999 & * & $*$ & * & * & $*$ & $*$ \\
\hline & 2002 & 30 & 42 & 72 & 7 & 5 & 12 \\
\hline \multirow[t]{2}{*}{ June } & 1999 & 281 & 173 & 454 & 18 & 14 & 32 \\
\hline & 2002 & 111 & 97 & 208 & 6 & 3 & 9 \\
\hline \multirow[t]{2}{*}{ July } & 1999 & 382 & 212 & 594 & 24 & 18 & 42 \\
\hline & 2002 & 121 & 87 & 208 & 7 & 2 & 9 \\
\hline \multirow[t]{2}{*}{ August } & 1999 & 288 & 176 & 464 & 19 & 11 & 30 \\
\hline & 2002 & 130 & 74 & 204 & 17 & 4 & 21 \\
\hline \multirow[t]{2}{*}{ September } & 1999 & 212 & 194 & 406 & 30 & 15 & 45 \\
\hline & 2002 & 140 & 64 & 204 & 15 & 3 & 18 \\
\hline \multirow[t]{2}{*}{ October } & 1999 & 304 & 207 & 521 & 50 & 18 & 68 \\
\hline & 2002 & * & * & * & * & $*$ & * \\
\hline \multirow[t]{2}{*}{ November } & 1999 & 385 & 270 & 655 & 62 & 24 & 86 \\
\hline & 2002 & $*$ & $*$ & $*$ & * & $*$ & $*$ \\
\hline \multirow[t]{2}{*}{ December } & 1999 & 634 & 390 & 1024 & 120 & 60 & 180 \\
\hline & 2002 & 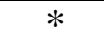 & . & $*$ & $*$ & $*$ & 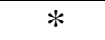 \\
\hline
\end{tabular}

* No data available 